CT Conebeam là 11,6\%

- Đường kính trung bình của lỗ cằm phụ là

$1,02 \pm 0,13 \mathrm{~mm}$

- Khoảng cách trung bình từ lỗ cằm phu tới lỗ cằm là 4,85 $\pm 1,24 \mathrm{~mm}$

- Chiếu dài trung bình của đường đi lỗ cằm phụ là 5,05 $\pm 1,53 \mathrm{~mm}$

- Vi trí lỗ cằm phu thường găp nhất là vị trí sau lỗ cằm với tỷ lệ $62,5 \%$

\section{TÀI LIÊU THAM KHẢO}

1. Trân Việt Hà, Nghiên cứu giải phẫu ống răng dưới trên phim CT Conebeam ở người trưởng thành, Đại học Y Hà Nội, 2014

2. Đồng Thanh Thiện, Nhận xét hình thái ống răng dưới theo ba chiều không gian và mối liên quan với các chân răng hàm dưới trên phim CT Conebeam, Đại học Y Hà Nội, 2013

3. Kalender A., Orhan K., Aksoy U., "Evaluation of the mental foramen and accessory mental foramen in
Turkish patients using cone-beam computed tomography images reconstructed from a volumetric rendering program", Clinical Anatomy, 2012

4. Katakami K., Mishima A., Shiozaki K., Shimoda S., Hamada Y., et al., "Characteristics of accessory mental foramina observed on limited cone-beam computed tomography images", Journal of Endodontics, 2008

5. Naitoh M., Yoshida K.,Nakahara K., Gotoh K., Ariji E., "Demonstration of accessory mental foramen using rotational panoramic radiography compared with cone-beam computed tomography", Clinical Oral Implants Research Journal, 2011

6. Paraskevas G., Mavrodi A., Natsis K., "Accessory mental foramen: an anatomical study on dry mandibles and review of the literature", The Journal of Oral and Maxillofacial Surgery, 2015

7. Naitoh M., Hiraiwa Y., Aimiya H., Gotoh K., Ariji E., "Accessory mental foramen assessment using cone-beam computed tomography", Oral Surgery, Oral Medicine, Oral Pathology, Oral Radiology, and Endodontology, 2009

\title{
NHÂN MộT TRƯờNG HỢP U MÕ̃ TUỶ LỚN VÙNG CỔ PHẪU THUẬT TẠI BỆNH VIÊ̂N VIỆT ĐỨC
}

\section{TÓM TẮT}

Tổng quan: Hâu hết các u mõ tủy sống được báo cáo trong y văn là u dưới màng cứng, ngoài tủy, và u mõ nội tủy thực sự là rất hiếm. Chúng tôi trình bày môt trường hợp u mõ̃ trong tủy sống của vùng cổ với phần mở rộng trên nhiều đoạn tủy sống. Trên phim công hưởng từ (MRI) cho thấy một u mỡ nôi tủy của tủy sống cổ với cường độ tín hiệu T1 và T2 cao. Đánh giá hình ảnh MRI rất quan trong trong việc phát hiên các u mỡ nội tủy có thể xuất hiện mà không có bất kỳ thiếu hụt thần kinh nào ở giai đoạn đâu. Chẩn đoán sớm có thể dẫn đến việc ngăn ngừa sự suy giảm không thể phục hồi của các chức năng thẩn kinh. Mô tả trường hợp: Bệnh nhân nam 29 tuổi, không có tiền sử rối loạn chức năng cột sống, có biểu hiện liệt cứng tứ chi tiến triển. Cộng hưởng từ ghi nhận u mõ̃ nội tủy lớn vùng cổ. Sau phẫu thuật cắt bỏ một phân tổn thương nội tủy, bệnh nhân đã் cải thiện về mặt thần kinh.

\section{SUMMARY \\ HUGE CERVICAL INTRAMEDULLARY LIPOMA SURGERY AT VIET DUC HOSPITAL: CASE REPORT}

${ }^{1}$ Bệnh viện Hữu nghị Việt Đức

Chịu trách nhiệm chính: Trân Sơn Tùng

Email: trantung.hmu@gmail.com

Ngày nhận bài: 22.6.2021

Ngày phản biên khoa hoc: 18.8.2021

Ngày duyệt bài: 25.8.2021
Background: Most of the spinal cord lipomas reported in the literature are intradural extramedullary, and true intramedullary lipomas are very rare. We present a case of intramedullary spinal cord lipoma of the cervical region with extensions over many spinal segments. Magnetic resonance (MR) examination showed an intramedullary lipoma of the cervical spinal cord of both high T1 and T2-weighted signal intensity and suppression on fat saturation sequence. MR imaging assessment is critical in the detection of intramedullary lipomas which may present without any neurological deficit at an early stage. Early diagnosis may lead to prevention of the irreversible deterioration of neurological functions. Case description: A 29-year-old male, without a history of spinal dysraphism, presented with a progressive spastic quadriparesis. This was attributed to magnetic resonance documented large intramedullary cervical lipoma. Following partial intramedullary surgical debulking of the lesion, the patient neurologically improved.

Key-words. Spinal cord tumor, Lipoma

\section{I. ĐĂT VẤN ĐỀ}

U mõ tại tuỷ sống thường xuất hiện bên ngoài tuỷ, hay gặp nhất ở đoạn tuỷ thắt lưngcừng ở các bệnh nhân có dị tật ống sống. Những tổ chức u mỡ nằm hoàn toàn bên trong tuỷ sông cực kì hiếm gặp, chiếm dưới 1\%[3] trong tổng số tất cả các tổn thương tuỷ sống. Do những trường hợp này u nằm trong tuỷ sống, nên sau phẫu thuật loại bỏ u, bệnh nhân có thể chỉ phục 
hồi một phần chức năng thần kinh [6].

Trong bài viết này, chúng tôi báo cáo về một bệnh nhân nam 29 tuổi, được chẩn đoán u mõ nội tuỷ đoạn tuỷ cổ, sau mổ loại bỏ bán phần khối u có cải thiện chức năng.

\section{CA LÂM SÀNG}

Bệnh nhân nam 29 tuổi, đau cổ, tê tay chân 6 tháng, 1 tháng gần đây triệu chứng đau tăng dần, kèm theo yểu tứ chi. Bệ̀nh nhân đến khám trong tình trạng mất cảm giác từ nền cổ trở

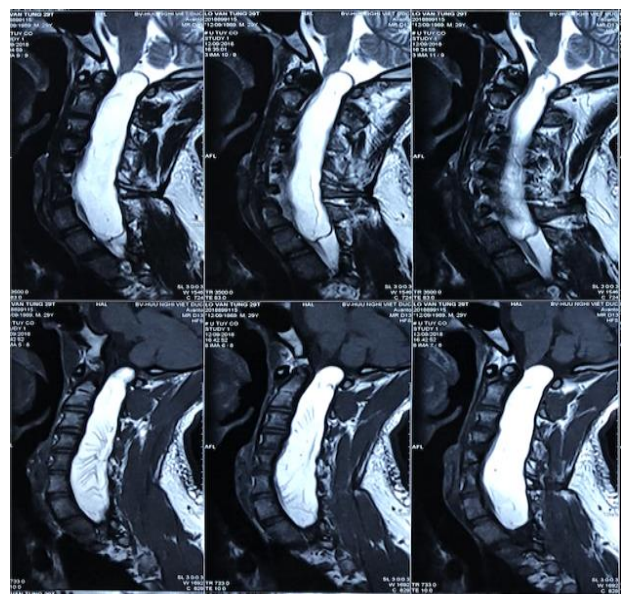

Chúng tôi tiến hành phẫu thuật cột sống cổ lối sau. Rach da rộng rãi từ ư chẩm ngoài đến ngang mức D2. Bóc tách và bộc lộ toàn bộ phần gai và cung sau $C 1$ đến $D 1$. Kiểm tra thấy hình thái cột sống vẹo nhiều sang bên phải (Đã được phát hiện trên phim chụp cộng hưởng từ trước đó). Cung sau C1 đến D1 được tiến hành mở rộng rãi, thành một khối nhờ sự hỗ trợ của khoan cắt cung saú. Đánh giá trong mổ khối u tương xứng với hình ảnh chụp cộng hưởng từ, xuống, giảm và mất vận động tứ chi. Cơ lực 2 tay là $3 / 5$, chân là $2 / 5$, đi lại cần có xe lăn hỗ trợ.

Cộng hưởng từ thấy hình ảnh khối nằm trong ống sống bắt đầu từ $C 0$ đến $D 1$, kích thước $13 * 3 \mathrm{~cm}$, tăng tín hiêu đồng nhất trên $\mathrm{T} 1 \mathrm{~W}$ và T2W, giảm tín hiệu hoàn toàn trên chuỗi xung xoá mõ̃, sau tiêm không ngấm thuốc. Khối chiếm chỗ và đè đẩy cấu trúc tuỷ cổ tương ứng không quan sát rõ hình thái tuỷ. Các đặc điểm này phù hợp với tính chất khối u mõ.

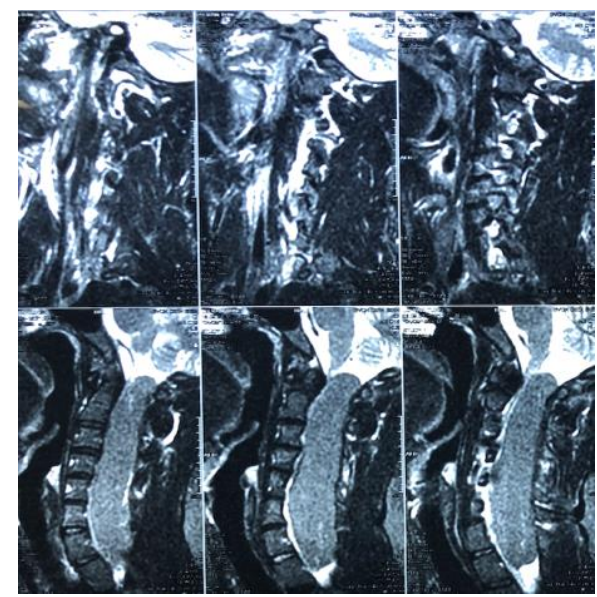

khối u kích thước $13 \mathrm{~cm}$, màu vàng nhạt, mật độ u mềm và tăng sinh mạch ít. Khối u nằm dưới màng nhện, dính chặt và đẩy toàn bộ tổ chức tuỷ sống ra trước, do không có mặt cắt ranh giới rõ ràng giữa khối u và mô lành nên chúng tôi chỉ tiến hành cắt bỏ u tối đa (có sử dụng dao cắt siêu âm), cùng với tạo hình màng cứng. Phần cung sau cắt ra được chúng tôi tạo hình lại bằng nẹp và vis nhằm khôi phục lại giải phẫu phần ống tuỷ mà vẫn đạt hiệu quả giải ép.
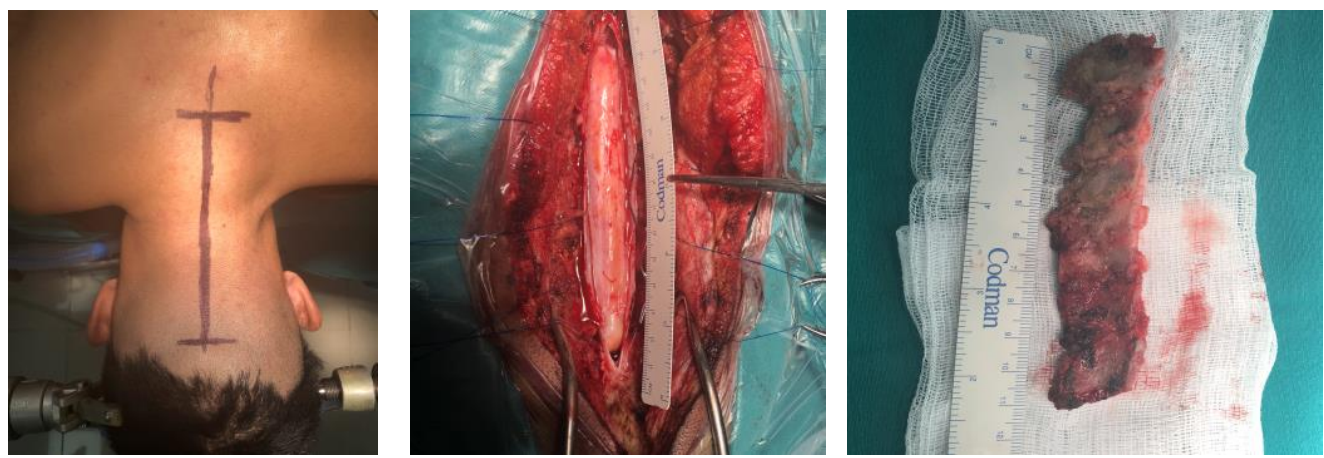

Bệnh nhân sau mổ diễn biến tốt và được xuất viện sau mổ 07 ngày với sự cải thiện rõ rệt về triệu chứng lâm sàng, bệnh nhân có thể đứng và đi lại với nạng hoặc người diu. Cảm giác được phục hồi ngay ngày thứ 3 sau mổ. Trên phim chụp kiểm tra cho thấy phần lớn khối u được lấy bỏ, phần tồn dư dính vào mặt sau tuỷ không đáng kể và nhìn thây được hình thái tuỷ sông trên phim chụp. 


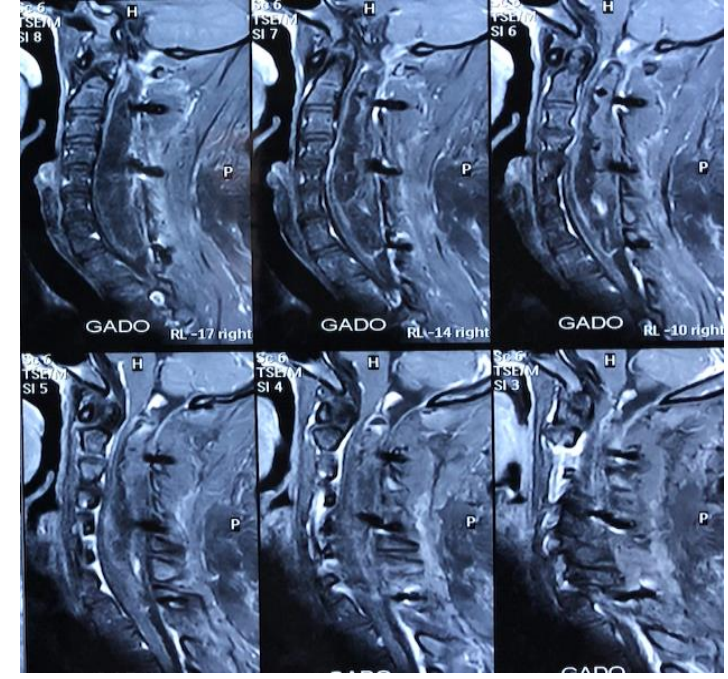

\section{BÀN LUÂN}

U mõ tại tuỷ sống là tổn thương tương đối hiếm gặp và chiếm tỷ lệ thấp trong số u tuỷ sống nói chung và u tuỷ cổ nói riêng[1][3]. Trong các nghiên cứu cho thấy đa số các khối u mõ xuất hiện tại vị trí ngoài màng tuỷ và hay gặp nhất ở đoạn tuỷ cùng/thắt lưng. Các khối u phát sinh ở đoạn tuỷ cổ đặc biệt là các khối u dưới màng tuỷ thường ảnh hưởng nghiêm trọng đến chức năng tuỷ và do vậy tiên lượng tương đối nghèo nàn[2]. Bên cạnh đó trong trường hợp này bệnh nhân là người dân tộc thiểu số, việc khám và phát hiện bệnh sớm không được thực hiện, tình trạng bệnh nhân khi đến với chúng tôi đã ở giai đoạn nặng.

Phôi thai học. Hầu hết các trường hợp u mõ tuỷ sống được báo cáo trong y văn đều là tổn thương ngoài tuỷ[1][3]. Chúng thường bắt đầu do sự di chuyển của các tế bào có nguồn gốc trung mô đến ống sống nguyên thuỷ trước khi ống sống kịp đóng kín trong quá trình phát triển phôi[1]. Triệu chứng của các u này thường biểu hiện tữ rất sớm và gồm hai pha chính: pha đầu tiền bắt đầu trước khi trẻ 5 tuổi, biểu hiện liệt tứ chi hoặc hội chứng yếu chi ở trẻ nhỏ do chấn thương tuỷ sống ngay lúc sinh. Giai đoạn 2 xảy ra do tăng sinh mô mõ trong quá trình phát triển, trong khoảng những năm 11-50 tuổi[3].

Biểu hiện lâm sang. Trên lâm sàng, các khối u mõ nội tuỷ đoạn tuỷ cổ biểu hiện mất phối hợp vận động, đau cổ, mất cảm giác, yếu liệt tăng dẩn; điển hình như ca bệnh được báo cáo. Ở bệnh nhân lớn tuổi, các triệu chứng có xu hướng biểu hiện không quá dữ dội, gợi ý đến bệnh lý tuỷ tiến triển chậm, đôi khi các triệu chứng này hay bị bỏ qua, càng làm chậm trễ cho

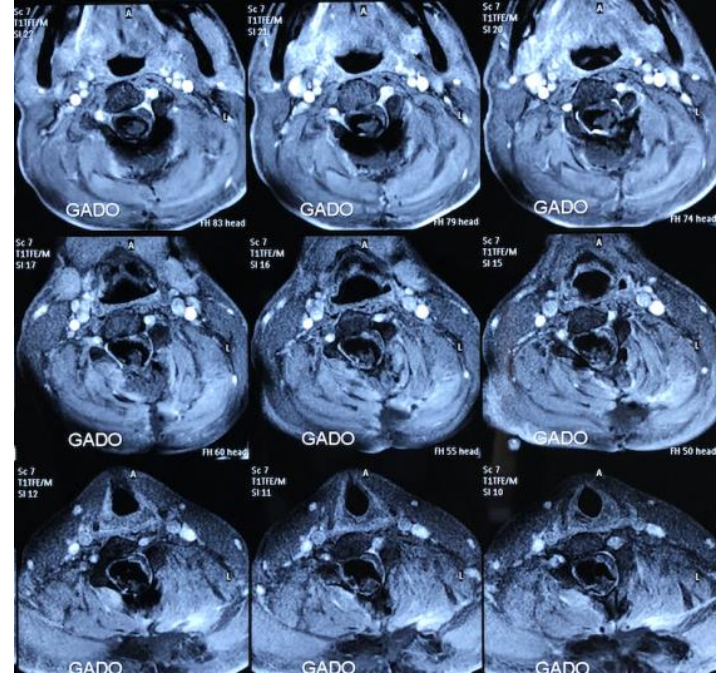

quá trình phát hiện và điêu trị bệnh [4]. Khi chèn ép đạt đển mức độ cực đại, bệnh lý tuỷ mới bắt đầu biểu hiện rõ rệt dần trên bệnh nhân. Ở giai đoạn này, cấu trúc tuỷ bị thoái hoá do chèn ép, giảm tưới máu, gây nhiêu khó khăn trong điều trị nhất là phục hồi chức năng sau phẫu thuật.

Chẩn đoán và điêu trị. Chẩn đoán và điêu trị sớm là yếu tố tối quan trọng và mang tính chất quyết định nhằm giảm thiểu những hậu quả không khắc phục được khi chèn ép tuỷ cổ diễn ra lâu dài.

Trên ảnh cộng hưởng từ, u mõ̃ biểu hiện tăng tín hiệu trên ảnh $T 1 W$ và giảm tín hiệu trên $T 2 W$, với hiện tượng đảo tín hiệu nhẹ dưới chuỗi xung phục hồi đảo nghịch $\mathrm{T} 1$ ngắn; các đặc điểm này gợi ý đến tổ chức giàu chất béo[1][3]. Biện pháp tối ưu được lựa chọn trong đa số trường hợp là giải ép nhưng không cắt hết u nhằm tránh sự suy yếu chức năng thần kinh sau này, do những khối u này phần ranh giới với mô lành rất mờ nhạt[4]. Siêu âm trong mổ cũng là một phương pháp hiệu quả giúp xác định độ thâm nhiếm của khối u, điện thế kích thích cảm giác tương đương giúp tránh gây tổn thương cho các cấu trúc thần kinh[5]. Điện thế kích thích vận động cũng có thể được sử dụng thường xuyển nểu cần cắt lại khối u, tuy nhiên trong điều kiện thực tế việc triển khai những phương pháp trên còn nhiều hạn chế, do vật tư trang thiết bị hiện còn thiếu thốn. Việc cắt bỏ phần lớn khối u, cùng với giải ép giúp giảm nhe triệu chứng một cách lâu dài.

Một số phẫu thuật viên đề xuất dùng laser $\mathrm{CO}_{2}$ nhằm gây bốc hơoi các tổ chức thương tổn mà không ảnh hưởng trực tiếp tới tuỷ sống[5]. Tuy nhiên hiện chưa có nhiều nghiên cứu đánh giá về hiệu quả cũng như mức độ an toàn của phương pháp này. 


\section{KẾT LUẬN}

U mõ nội tuỷ đoạn tuỷ cổ là bênh tương đối hiếm gặp, biểu hiện điển hình với tình trạng yếu liệt tứ chi tăng dân, có thể kèm theo các rối loạn vể cảm giác. Chụp cộng hưởng từ là phương pháp chủ yếu để chẩn đoán bệnh. Về phương pháp điêuu trị, việc cắt bán phân u được ưu tiên hơn là cắt toàn bộ mô u nhằm tránh tổn thương chức năng thân kinh. Tạo hình màng cứng giúp tăng hiệu quả giải ép lâu dài.

\section{TÀI LIẸU THAM KHẢO}

1. Ammerman BJ, Henry JM, De Girolami U, Earle KM. Intradural lipomas of the spinal cord. A clinicopathological correlation. J Neurosurg 1976; 44: 331-336.
2. Bhatoe HS, Singh $P$, Chaturvedi A, Sahai $K$, Dutta V, Sahoo PK. Nondysraphic intramedullary spinal cord lipomas: A review. Neurosurg Focus. 2005; 18:EC P1.

3. Lee $M$, Rezai $A R$, Abbott $R$, Coelho $D H$ Epstein FJ. Intramedullary spinal cord lipomas. J Neurosurg. 1995;82:394-400.

4. Naim Ur R, Salih MA, Jamjoom AH, Jamjoom ZA. Congenital intramedullary lipoma of the dorsocervical spinal cord with intracranial extension: Case report. Neurosurgery. 1994; 34:1081-3.discussion 1084.

5. Pathi $\mathbf{R}$, Kiley $\mathbf{M}$, Sage $\mathbf{M}$. Isolated spinal cord lipoma . J Clin Neurosci 2003; 10:692-694.

6. Sanli AM, Türkog lu E, Kahveci R, Sekerci Z. Intradural lipoma of the cervicothoracic spinal cord with intracranial extension. Childs Nerv Syst 2010; 26:847-852.

\title{
CHẤT LƯợNG CUộC SỐNG VÀ MộT Số YẾU Tố LIÊN QUAN Ở TRẺ VI THÀNH NIÊN 10-15 TUỔI ĐIỀU TRI ARV NGOẠI TRÚ TẠI BỆNH VIỆN NHI TRUNG ƯO'NG
}

\author{
Nguyễn Thị Hiền ${ }^{1}$, Nguyễn Văn Lâm², Mattias Larsson ${ }^{3}$, Linus Olson ${ }^{3}$,
} Nguyễn Thị Kim Chúc ${ }^{4}$, Trần Khánh Toàn ${ }^{4}$

\section{TÓM TẮT}

Muc tiêu: Mô tả chất lượng cuộc sống (CLCS) và một số yếu tố liên quan ở trẻ vị thành niên 10-15 tuổi nhiếm HIV đang điêu trị ARV ngoaii trú tại Bệnh viện Nhi trung ương. Đối tượng và phương pháp: Nghiên cứu cắt ngang được thực hiên trên 190 trẻ từ 10-15 tuổi nhiễm HIV đang được quản lý điêuu trị ARV ngoai trú tai Bênh viên Nhi trung ương từ 6-12/2020. CLCS được đánh giá bằng công cụ PedsQL 4.0 với 23 câu hỏi liền quan đến 4 lính vực về thể chất, tình cảm, xã hội và học tập. Điểm số càng cao tương ứng với CLCS càng tốt. Kết quả: Điểm trung bình CLCS chung 72,2 ; về sức khỏe thể chất 80,3 ; sức khỏe tâm lý xã hội 75,6; xã hội 82,2; cảm xúc 76,3; và học tập 68,3. Tỷ lệ CLCS tốt tính chung là 56,8\%; về sức khỏe thể chất $67,9 \%$; sức khỏe tâm lý xã hội $57,4 \%$; về xã hội $73,2 \%$, cảm xúc $57,9 \%$ và học tập $45,3 \%$. Trẻ thuộc các hộ gia đình nghèo, trẻ có NCS có học vẫn thấp (từ THCS trở xuống) và trẻ có thời gian từ nhà đến phòng khám từ 60 phút trở lên có $C L C S$ thấp hơn $(p<0,05)$. Kết luân: Trẻ vị thành niên nhiễm HIV đang điều trị ARV có CLCS cao ở hầu hết các lĩnh vực, trừ lĩnh vực học tập. Hộ gia đình nghèo, học vấn của NCS thấp và

\footnotetext{
${ }^{1}$ Trường Đại học Y Dược - ĐH Thái Nguyên ²Bênh viện Nhi Trung Ương

${ }^{3}$ Viện Karolinska, Thụy Điển, ${ }^{4}$ Đại học Y Hà Nội

Chịu trách nhiệm chính: Nguyễn Thị Hiền

Email: Hiennguyentn92@gmail.com

Ngày nhận bài: 18.6.2021

Ngày phản biện khoa học: 17.8.2021

Ngày duyệt bài: 24.8.2021
}

thời gian tiếp cận phòng khám dài là những yếu tố liên quan đến CLCS thấp ở trẻ vị thành niên.

Tư khóa: Chất lượng cuộc sống, vị thành niên, HIV, ARV, PedsQL.

\section{SUMMARY \\ QUALITY OF LIFE AND RELATED FACTORS IN HIV-INFECTED ADOLESCENTS AGED 10- 15 YEARS ON ANTIRETROVIRAL TREATMENT AT THE NATIONAL CHILDREN'S HOSPITAL IN 2020}

Objectives: To describe the quality of life (QoL) and its related factors in HIV-positive adolescents aged 10-15 years on antiretroviral treatment (ART) at the National Children's Hospital. Subjects and methods: A descriptive cross-sectional study of 190 HIV-infected children aged $10-15$ years taking ART at the National Children's Hospital from June to December 2020. The 23-item PedsQL ${ }^{T M}$ Generic Core Scales were used to measure 4 core dimensions of health: physical, emotional, social and school functions. Results: The average scores were 72.2 for total QoL; 80.3 for physical health; 75.6 for psychosocial health; 76.3 for emotional function; 82.2 for social function; and 68.3 for school function. The rates of good QoL were $56.8 \%$ in total; $67.9 \%$ for physical function; $57.4 \%$ for psychosocial health; $57.9 \%$ for emotional function; $73.2 \%$ for social function; and $45.3 \%$ for school function. Children living in poor families, who having caregivers with low education (from lower secondary school) and those who need at least 60 minutes to reach the clinic had lower $\mathrm{QoL}(\mathrm{p}<0.05)$. Conclusion: HIV-infected 